\title{
A pilot study of workplace violence towards paramedics
}

\author{
Malcolm Boyle, Stella Koritsas, Jan Coles, Janet Stanley
}

Emerg Med J 2007;24:760-763. doi: 10.1136/emj.2007.046789

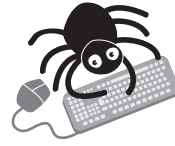

Supplementary file available at http://emj.bmi.com/ supplemental

See end of article for authors' affiliations

....................

Correspondence to: Mr Malcolm Boyle, Monash University, Department of Community Emergency Health and Paramedic Practice, PO Box 527 , Frankston 3199, Victoria, Australia; Mal.Boyle@med. monash.edu.au

Accepted 19 June 2007
Background: International studies have shown that some $60 \%$ of paramedics have experienced physical violence in the workplace, and between $21-78 \%$ have experienced verbal abuse. To date, there is no Australian literature describing Australian paramedics' experience of workplace violence.

Objective: To identify the percentage of paramedics who had experienced six different forms of workplace violence.

Methods: A questionnaire was developed to explore paramedics' experience of workplace violence. Six forms of violence were included: verbal abuse, property damage or theft, intimidation, physical abuse, sexual harassment, and sexual assault. The questionnaire also included a series of demographic questions. The questionnaire was piloted using a reference group and changes made accordingly. The questionnaire was distributed to 500 rural Victorian paramedics and $\mathbf{4 3 0}$ metropolitan South Australian paramedics. Ethics approval was granted for this study.

Results: The overall response rate was $28 \%$, with $75 \%$ being male and $25 \%$ female. The median age of respondents was 40.7 years, range 21-62 years. The median number of years experience as a paramedic was 14.3 years, range 6 months to 39 years. There were $87.5 \%$ of paramedics exposed to workplace violence. Verbal abuse was the most prevalent form of workplace violence $(82 \%)$, with intimidation $(55 \%)$, physical abuse (38\%), sexual harassment (17\%), and sexual assault (4\%).

Conclusion: This study lays the foundation for further studies investigating paramedic experience of workplace violence. This study demonstrates that workplace violence is prevalent for paramedics and highlights the need for prevention and education within the profession.
$\mathrm{V}$ iolent and aggressive behaviour is reported to be widely experienced across health care and welfare disciplines in Australia. ${ }^{1-3}$ Where it has been examined, it is so pervasive in these occupations that it is often seen as "part of the job" and therefore "acceptable" rather than a harmful activity needing assessment and management in the work environment. ${ }^{45}$ Recent studies in Australia reported occupational homicides as $2-3 \%$ of all traumatic workplace deaths; $24 \%$ occurred in the community service sector which includes medical services. ${ }^{356}$ Studies from Australia, the UK and the USA report that occupations with substantial face to face contact are particularly at risk of client initiated violence. ${ }^{3}$ Women experience higher levels of verbal aggression and sexual abuse, while men experience more overt threats and physical assaults. ${ }^{7}$

Studies of emergency service workers in the USA reported that $61 \%$ had been assaulted in the field and $25 \%$ had sustained an injury from violence. ${ }^{89}$ A Swedish study found $80.3 \%$ of emergency paramedics had been threatened or subject to violence, $67 \%$ subjected to physical violence, and over one third had experienced threats of violence every 3 months, usually from a patient, a relative or a friend of the patient. ${ }^{10}$ Suserund found that $98.1 \%$ of ambulance paramedics felt that threats of violence or violence from the patient altered the relationship with the patient. ${ }^{10}$ Eighty per cent felt the care provided to patients was altered by threats or violence from relatives. ${ }^{10}$

We reviewed the literature, which included searching the Medline, EMBASE, CINAHL electronic databases and reference lists of retrieved articles, and were unable to locate any published Australian literature that described Australian ambulance paramedics' experience of workplace violence. The objective of this study was to identify the types of violence paramedics experienced within the workplace in Australia.

\section{METHODS}

This pilot study utilised a cross sectional study methodology using a convenience sample to elicit paramedics' responses of experience to workplace violence.

The setting for the study was the paramedics from the rural ambulance service in Victoria, Rural Ambulance Victoria (RAV), and the metropolitan staff from the South Australian Ambulance Service (SAAS).

Victoria is a south eastern state of Australia covering approximately 227590 square kilometres with an approximate population of some 4.9 million people. ${ }^{11}$ South Australia is a southern state of Australia covering approximately 984377 square kilometres with an approximate population of some 1.5 million people. ${ }^{11}$

RAV has some 113 ambulance stations with approximately 310 ambulances and a staff of approximately 1100, including volunteer staff located in the more isolated and low workload areas of the state. ${ }^{12}$ The SAAS has some 104 ambulance stations with approximately 200 ambulances and a staff of approximately 1900, including volunteer staff located in the more isolated and low workload areas of the state. In the metropolitan area, SAAS has 19 ambulance stations and an on road staff of approximately $430 . .^{13}$

We defined workplace violence as violence that was associated with work. As such it included violence that occurred in the ambulance station or offices where management was housed, the ambulance itself, a health care facility, and the incident location.

Workplace violence perpetrators included, but were not limited to, other paramedic staff (including all management levels), the patient, the patient's relative or friend, incident

Abbreviations: RAV, Rural Ambulance Victoria; SAAS, South Australian Ambulance Service 
Table 1 Violence definitions

\begin{tabular}{|c|c|}
\hline Violence type & Definition \\
\hline Verbal abuse & $\begin{array}{l}\text { A patient/client, their friend/s, family member/s, other } \\
\text { professional/s or work colleague/s using offensive } \\
\text { language, yelling or screaming with the intent of offending } \\
\text { or frightening you. It can include threats or abuse over the } \\
\text { phone, but excludes sexual harassment and sexual assault }\end{array}$ \\
\hline $\begin{array}{l}\text { Property } \\
\text { damage or } \\
\text { theft }\end{array}$ & $\begin{array}{l}\text { A patient/client, their friend/s, family member/s, other } \\
\text { professional/s or work colleague/s, causing damage to, or } \\
\text { stealing property belonging to you, your family or your } \\
\text { workplace. It includes damage to or theft of a vehicle, } \\
\text { personal effects, home contents, office equipment, and } \\
\text { supplies, or office furnishings. Attempted theft of the above } \\
\text { items is also included }\end{array}$ \\
\hline Intimidation & $\begin{array}{l}\text { A patient/client, their friend/s, family member/s, other } \\
\text { professional/s or work colleague/s purposely threatening, } \\
\text { following you, using gestures to purposely offend or } \\
\text { frighten you }\end{array}$ \\
\hline Physical abuse & $\begin{array}{l}\text { A patient/client, their friend/s, family member/s, other } \\
\text { professional/s or work colleague/s physically attacking } \\
\text { you, or attempting to attack you. It includes behaviours such } \\
\text { as punching, slapping, kicking or using a weapon or other } \\
\text { object with the intent of causing bodily harm }\end{array}$ \\
\hline $\begin{array}{l}\text { Sexual } \\
\text { harassment }\end{array}$ & $\begin{array}{l}\text { Any form of sexual propositioning or unwelcome sexual } \\
\text { attention from a patient/client, their friend/s, family } \\
\text { member/s, other professional/s or work colleague/s. It } \\
\text { includes behaviours such as humiliating or offensive jokes } \\
\text { and remarks with sexual overtones, suggestive looks or } \\
\text { physical gestures, inappropriate gifts or requests for } \\
\text { inappropriate physical examinations, pressure for dates, } \\
\text { and brushing, touching or grabbing excluding sexual } \\
\text { touching (for example, the genital or breast area). }\end{array}$ \\
\hline Sexual assault & $\begin{array}{l}\text { Any forced sexual act, rape or indecent assault perpetrated } \\
\text { by a patient/client, their friend/s, family member/s, other } \\
\text { professional/s or work colleague/s. It includes brushing, } \\
\text { touching or grabbing of the genitals or breast. It also } \\
\text { includes attempted sexual assault }\end{array}$ \\
\hline
\end{tabular}

bystanders, other emergency service staff (fire and police), and health care facility staff.

A questionnaire was developed to explore paramedics' experience of violence (see supplementary file available at http://emj.bmj.com/supplemental). The questionnaire consisted of five specific sections. The first section covered the experience of the paramedic to six forms of workplace violence as defined by Tolhurst et al ${ }^{14}$-verbal abuse, property damage or theft, intimidation, physical abuse, sexual harassment, and sexual assault. The definitions of violence types were included in the questionnaire and are listed in table 1 . The second section of the questionnaire covered the paramedic's description, using three qualitative questions, of how they felt personally after experiencing an episode of violence in the workplace, as defined in the first section. The third section covered the paramedic's response to the violent incident(s). The fourth section covered the Impact of Event Scale which measured the paramedic's response to a violent workplace event in the following 7 days. ${ }^{15}$ The fifth section covered general demographic information like age, gender, qualification, and work location.

The questionnaire was piloted on a group of rural paramedics. Following the return of the questionnaires and comments, changes were made to the questionnaire.

The questionnaire was then distributed by the respective ambulance service (RAV and SAAS) to their staff. RAV randomly distributed 500 questionnaires to their paramedics with SAAS distributing 430 questionnaires to all their metropolitan paramedics. Paramedics completed the questionnaire and returned it using a reply paid envelope to the research assistant. There was no follow up letter sent to the paramedics to encourage them to complete the questionnaire.

Descriptive data analysis was undertaken using SPSS (Statistical Package for the Social Sciences Version 14.0, SPSS Inc, Chicago, Illinois, USA). Additional statistics, including proportional differences, mean confidence intervals and p values, were undertaken using EpiCalc 2000 (Version 1.02, Brixton Books, 1998).

Descriptive statistics were used to summarise the data, gender differences were analysed using $\chi^{2}$ test for independence or Fisher's exact test, comparisons between groups were undertaken using a two-tailed $\mathrm{t}$ test, and differences in proportions were used to compare metropolitan and rural cohorts. The results are considered significant if the $\mathrm{p}$ value was $<0.05$; all confidence intervals (CI) were $95 \%$.

Ethics approval for this study was granted by the Monash University Standing Committee for Ethics in Research on Humans.

\section{RESULTS}

The questionnaire was distributed to 500 rural paramedics via RAV. There were 152 questionnaires returned, four of which were returned to the researchers due to a change of address and hence excluded. The response for RAV paramedics was therefore $29.6 \%$. There were 430 questionnaires distributed to metropolitan paramedics via the SAAS. Of these, 108 were returned with one excluded due to a change of address. The response rate was therefore $25.1 \%$. A total of 930 questionnaires were distributed with an overall response rate of $28 \%$.

The study of paramedics consisted of $74.5 \%$ males, $24.3 \%$ females, and $1.2 \%$ not defined. Information about paramedics' ethnicity was not collected as it is particularly difficult to define. The median age of respondents was 41 years, range $21-$ 62 years. The median number of years that paramedics had worked as paramedic was 14 years, range 6 months to 39 years. The median number of hours worked per week was $42 \mathrm{~h}$, range 19-90 h. The median hours of direct patient contact was $24.5 \mathrm{~h}$, range no contact time to $66 \mathrm{~h}$.

The highest qualification obtained by the majority of paramedics was qualified ambulance paramedic/officer, with a small number of students identified as outlined in table 2 .

Table 3 presents the number and percentage of paramedics who had experienced workplace violence in the last 12 months, according to place of practice (metropolitan versus rural, and then overall).

Of the paramedics surveyed, $87.5 \%$ had experienced at least one form of violence associated with the workplace in the last 12 months.

Table 3 demonstrates that the most common form of violence experienced by paramedics overall was verbal abuse followed by intimidation and physical abuse. The least common form of violence was sexual assault. The only statistically significant results were the comparison between metropolitan and rural paramedics for those who experienced sexual harassment and sexual assault; all other comparisons between metropolitan and

Table 2 Qualifications of paramedics

\begin{tabular}{lrr}
\hline Paramedics qualification & $\mathbf{n}$ & \multicolumn{1}{l}{$\%$} \\
\hline MICA paramedic/IC paramedic & 71 & 27.9 \\
Qualified ambulance paramedic/officer & 158 & 62.0 \\
Student paramedic & 12 & 4.7 \\
Student MICA/IC paramedic & 1 & 0.4 \\
\hline
\end{tabular}

IC, intensive care; MICA, mobile intensive care ambulance. 
Table 3 Paramedics who had experienced each form of violence in the last 12 months according to location of work

\begin{tabular}{|c|c|c|c|c|}
\hline & $\begin{array}{l}\text { Overall } \\
\mathrm{n}(\%)\end{array}$ & $\begin{array}{l}\text { Rural paramedics } \\
(n=148) \\
n(\%)\end{array}$ & $\begin{array}{l}\text { Metropolitan } \\
\text { paramedics } \\
(\mathrm{n}=107) \\
\mathrm{n}(\%)\end{array}$ & $\begin{array}{l}\text { Difference between metropolitan } \\
\text { and rural paramedics }\end{array}$ \\
\hline Verbal abuse & $210(82.4)$ & 117 (79) & 93 (86.9) & $\begin{array}{l}7.86, C l-2.10 \text { to } 17.82 \\
Z=1.46, p=0.145\end{array}$ \\
\hline Theft & 38 (14.9) & 18 (12.2) & 20 (18.7) & $\begin{array}{l}6.53, C l-3.35 \text { to } 16.41 \\
Z=0.27, p=0.21\end{array}$ \\
\hline Intimidation & $139(54.5)$ & 79 (53.4) & $60(56.1)$ & $\begin{array}{l}2.70, \mathrm{Cl}-10.48 \text { to } 15.87 \\
\mathrm{Z}=0.3, \mathrm{p}=0.765\end{array}$ \\
\hline Physical abuse & $96(37.6)$ & $48(32.4)$ & $48(44.9)$ & $\begin{array}{l}12.43, \mathrm{Cl}-0.45 \text { to } 25.30 \\
\mathrm{Z}=1.89, \mathrm{p}=0.059\end{array}$ \\
\hline Sexual harassment & $42(16.5)$ & $16(10.8)$ & $26(24.3)$ & $\begin{array}{l}13.49, \mathrm{Cl} 3.14 \text { to } 23.84 \\
Z=2.69, p=0.007\end{array}$ \\
\hline Sexual assault & $11(4.3)$ & $2(1.4)$ & $9(8.4)$ & $\begin{array}{l}7.06, \mathrm{Cl} 0.68 \text { to } 13.44 \\
Z=2.53, p=0.015\end{array}$ \\
\hline
\end{tabular}

rural paramedics were not statistically significant. These results indicate that more metropolitan paramedics experienced sexual harassment and sexual assault than rural paramedics.

The results from this point onwards represent aggregate data-that is, rural and metropolitan paramedic responses combined, classified according to gender.

Table 4 demonstrates that more female than male paramedics experienced sexual harassment and sexual assault. All other comparisons between male and female paramedics were not statistically significant.

Paramedics were asked to indicate how frequently, in the last 12 months, they experienced each form of violence. These results are presented in table 5 . It is clear that almost half the paramedics experienced verbal abuse a few times in the last 12 months, and one third experienced intimidation a few times in the last 12 months. Just over 3\% of paramedics reported experiencing verbal abuse on a daily basis and approximately $12 \%$ about once a week.

\section{DISCUSSION}

This pilot study is the first of its kind in Australia to investigate paramedics' experience of workplace violence. This study has revealed that paramedics commonly experience workplace violence, predominantly in the forms of verbal abuse and intimidation.

The reporting of workplace violence against paramedics has only occurred in relatively recent times. The first scientific report of violence against paramedics occurred in the early 1990s by Tintinalli and McCoy in the USA, and demonstrated that there were indeed violent acts committed against paramedics in the course of their duty. ${ }^{16}$

The rate of verbal abuse in the international studies varied from $21-78 \%$, and we found that $82 \%$ of paramedics had been verbally abused. ${ }^{17-19}$ Even though this is normally the most common type of workplace violence, it probably has the least long lasting effect on a paramedic; however, racial verbal abuse is a different matter and will effect different people in a variety of ways. There was no specific question about racial abuse in the current study.

The rate of physical violence previously reported is predominantly much higher, $2.9-79.5 \%$, compared to what we found. Several of the US studies specifically reported physical assault with a weapon; we did not specifically ask about assault with a weapon which may account for why our prevalence was much

Table 4 Paramedics experiencing violence according to gender

\begin{tabular}{|c|c|c|c|}
\hline & $\begin{array}{l}\text { Female paramedics } \\
(n=65)\end{array}$ & $\begin{array}{l}\text { Male paramedics } \\
(n=190)\end{array}$ & $\begin{array}{l}\text { Difference between female and male } \\
\text { paramedics }\end{array}$ \\
\hline Verbal abuse & $55(88.7 \%)$ & $152(80 \%)$ & $\begin{array}{l}8.71, C l-2.08 \text { to } 19.50 \\
Z=1.36, P=0.172\end{array}$ \\
\hline Property damage/theft & $9(14.8 \%)$ & $28(14.9 \%)$ & $\begin{array}{l}0.22, \mathrm{Cl}-10.96 \text { to } 11.40 \\
Z=-0.16, P=0.869\end{array}$ \\
\hline Intimidation & $37(61.7 \%)$ & $99(52.4 \%)$ & $\begin{array}{l}7.57, \mathrm{Cl}-7.62 \text { to } 22.77 \\
\mathrm{Z}=0.89, \mathrm{P}=0.372\end{array}$ \\
\hline Physical abuse & $28(45.9 \%)$ & $65(34.8 \%)$ & $\begin{array}{l}10.95, \mathrm{Cl}-4.22 \text { to } 26.15 \\
Z=1.40, P=0.161\end{array}$ \\
\hline Sexual harassment & $23(37.7 \%)$ & $18(9.5 \%)$ & $\begin{array}{l}27.62, \mathrm{Cl} 13.83 \text { to } 41.42 \\
\mathrm{Z}=4.92, \mathrm{P}<0.0001\end{array}$ \\
\hline Sexual assault & $7(11.5 \%)$ & $3(1.6 \%)$ & $\begin{array}{l}9.71, \mathrm{Cl} 0.57 \text { to } 18.86 \\
\mathrm{Z}=3.03, \mathrm{P}<0.002\end{array}$ \\
\hline
\end{tabular}


Table 5 Frequency with which each type of abuse was experienced over the last 12 months

\begin{tabular}{|c|c|c|c|c|c|}
\hline & $\begin{array}{l}\text { Once } \\
\text { (\%) }\end{array}$ & $\begin{array}{l}\text { A few } \\
\text { times } \\
(\%)\end{array}$ & $\begin{array}{l}\text { About } \\
\text { once a } \\
\text { month } \\
(\%)\end{array}$ & $\begin{array}{l}\text { About } \\
\text { once a } \\
\text { week } \\
(\%)\end{array}$ & $\begin{array}{l}\text { Daily } \\
\text { (\%) }\end{array}$ \\
\hline Verbal abuse & 5.1 & 43.1 & 19.6 & 11.8 & 3.1 \\
\hline Property damage or theft & 8.6 & 5.1 & 0.8 & 0.4 & - \\
\hline Intimidation & 7.5 & 34.9 & 7.5 & 3.9 & 0.8 \\
\hline Physical abuse & 17.3 & 18.8 & 1.2 & 0.4 & - \\
\hline Sexual harassment & 2.7 & 8.6 & 3.1 & 1.2 & 0.8 \\
\hline Sexual assault & 1.6 & 2.7 & - & - & - \\
\hline
\end{tabular}

lower than that reported by others. Indeed, assault with weapons on paramedics appears to be a rare occurrence in Australia compared to other countries such as the USA. ${ }^{96-21}$

There were two international studies that just reported paramedic exposure to violent acts; one study did not elaborate any further about the specific types of "violent acts". ${ }^{17}{ }^{19}{ }^{21}$ It is difficult to compare the violence exposure results in this study and the one by Grange and Corbett ${ }^{17}$ as it is hard to determine if they included violent acts as part of the total "ambulance runs" or just as part of the total violent acts.

This study is unique in that, unlike international studies, we reported specifically on paramedics' experience of sexual assault, sexual harassment, and intimidation in the workplace. International studies have not reported on these forms specifically, but it may be that they have been included in another form of violence such as physical assault or intimidation. Intimidation may be a precursor to sexual assault/ harassment; however, we are unable to determine this fact from the questionnaire data, and it would require a prospective study to help confirm this.

In this study the percentage of males was approximately $75 \%$, similar to a study in Sweden by Suserud et al, ${ }^{19}$ but less than two studies in the USA by Grange et $a l^{17}$ and Mock et al. ${ }^{18}$ There were two other US based studies that had male staff numbers between $55-60 \%{ }^{20}$; this could become the norm in the future as the intake of undergraduate paramedics in Victoria is predominantly females. The gender distribution of operational paramedics in South Australia is 60\% males and $40 \%$ females. $^{13}$

The median age of our respondents was $1-5$ years higher than those studies in the USA and Sweden ${ }^{17-20}$; likewise, the median years of experience is higher in our study by 3-5 years compared to the international studies. ${ }^{17-19}{ }^{21}$ Outside of formal education in handling workplace violence, the additional work experience identified in Australia may assist the paramedics in dealing with actual or potentially violent episodes. Australia fortunately does not have the level of violence highlighted in several of the US studies-for example, paramedics being threatened with dangerous weapons. ${ }^{1621}$

This study is limited by the ability of the paramedics to recall incidents of workplace violence. Some components of the questionnaire asked the paramedic to recall what had transpired in the preceding 12 months. Furthermore, using a single method of measurement (that is, self reports over a 12 month period) without corroboration from other external sources of information, such as observer ratings, may have limited the validity of our findings. The retrospective nature of the study and the return rate may mean that the results are not a true representation of the total paramedic population in both state areas.

\section{CONCLUSION}

This study demonstrates that paramedics do experience workplace violence and that there is a need for additional prospective studies to determine the actual prevalence of workplace violence. This study also highlights that there is a significant number of paramedics who experience sexual harassment/assault in the workplace by work colleagues. These results also highlight a need for education, especially for new paramedics fresh from a university education, about how to deal with workplace violence.

\section{ACKNOWLEDGEMENTS}

We like to thank the paramedics that took the time to complete and return the survey.

\section{Authors' affiliations \\ Malcolm Boyle, Monash University, Department of Community Emergency Health and Paramedic Practice, Frankston, Victoria, Australia \\ Stella Koritsas, Jan Coles, Monash University, Department of General \\ Practice, Notting Hill, Victoria, Australia \\ Janet Stanley, Brotherhood of St Laurence, Fitzroy, Victoria, Australia}

Funding: This project was funded by an internal Monash University, Faculty of Medicine, Nursing and Health Sciences research grant

Competing interests: None

\section{REFERENCES}

1 Stanley J, Goddard C. In the firing line: violence and power in child protection work. Chichester: John Wiley and Sons, 2002:88-92.

2 National Health and Medical Research Council. When it's right in front of you. Canberra: National Health and Medical Research Council, 2002:5-11.

3 Mayhew C, Chappell D. Occupational violence: types, reporting patterns, variations. Discussion paper. Canberra: Australian Institute of Criminology, 2001:1-14.

4 International Labour Organization. Framework guidelines for addressing workplace violence in the health sector. Geneva: International Labour Organization, 2002:1-29.

5 Perrone S. Violence in the workplace. Canberra: Australian Institute of Criminology, 1999:1-115.

6 National Occupational Health and Safety Commission. Program 1 report: occupational violence. Canberra: National Occupational Health and Safety Commission, 1999:4-6.

7 Chappell D, Di Martino V. Violence at work. Geneva: International Labour Office, 2000:3-27.

8 Corbett SW, Grange JT, Thomas TL. Exposure of prehospital care providers to violence. Prehosp Emerg Care 1998;2:127-31

9 Mechem CC, Dickinson ET, Shofer FS, et al. Injuries from assaults on paramedics and firefighters in an urban emergency medical services system. Prehosp Emerg Care 2002;6:396-401.

10 Suserund $B$, Blomquist $M$, Johansson I. Experiences of threats and violence in the Swedish Ambulance Service. Accid Emerg Nurs 2002;10:127-35.

11 Australian Bureau of Statistics. 3101.0 - Australian demographic statistics. 2005. http://www.abs.gov.au/ausstats/abs@archive.nsf/log?openagent\& 310104.xls\&3101.0\&Time\% 20Series\%20Spreadsheet\&8983C6CD67B20 A94CA2571EF007D65F2\&0 \&Mar\%202006\&2109.2006\&Latest (accessed 21 November 2005).

12 Rural Ambulance Victoria. Rural Ambulance Victoria annual report - 05. Ballarat: Rural Ambulance Victoria, 2005:68.

13 SA Ambulance Service Corporate Communications. SA Ambulance Service annual report 2005-2006. Eastwood: South Australian Ambulance Service, 2006:62.

14 Tolhurst H, Talbot J, Bell P, et al. After hours medical care and personal safety needs of rural general practitioners. Newcastle: University of Newcastle, 1999.

15 Horowitz M, Wilner M, Alvarez W. Impact of event scale: a measure of subjective stress. Psychosom Med 1979;41:209-18.

16 Tintinalli JE, McCoy M. Violent patients and the prehospital provider. Ann Emerg Med 1993;22:1276-9.

17 Grange JT, Corbett SW. Violence against emergency medical services personnel. Prehosp Emerg Care 2002;6:186-90.

18 Mock EF, Wrenn KD, Wright SW, et al. Anxiety levels in EMS providers: effects of violence and shifts schedules. Am J Emerg Med 1999;17:509-11.

19 Suserud BO, Blomquist $M$, Johansson I. Experiences of threats and violence in the Swedish Ambulance Service. Accident \& Emergency Nursing 2002;10:127-35.

20 Maguire BJ, Hunting KL, Guidotti TL, et al. Occupational injuries among emergency medical services personnel. Prehosp Emerg Care 2005;9:405-11.

21 Pozzi C. Exposure of prehospital providers to violence and abuse. $J$ Emerg Nurs $1998 ; 24: 320-3$. 